\title{
The Effect of Alcoholic and Aqueous Extract of Piper nigrum on the Larvae of Culex pipiens molestus Forskal (Diptera:Culicidae)
}

\author{
Aulfat T. Yaseen \\ Received 25/9/2018, Accepted 12/6/2019, Published 1/3/2020 \\ EY This work is licensed under a Creative Commons Attribution 4.0 International License.
}

@-

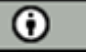

\begin{abstract}
The present study includes the effect of the ethanolic and aqueous extract of Piper nigrum against the third instar of Culex pipiens molestus (Diptera:Culicidae) in different concentrations: 1, $1.5 \mathrm{ppm}$ of ethanolic extracts of Piper nigrum causing 100\% mortality of larvae in the second day of treatment, while the concentrations 5\% of aqueous extracts of Piper nigrum caused $100 \%$ mortality of larvae in the second day of treatment. The concentration $2.5 \%$ caused $100 \%$ mortality of larvae after four days of treatment. The current study also detected the effect of $0.1 \%$ concentration of Piper nigrum aqueous extract. The effect of this concentration has been studied on the growth of the ovaries and their follicles along a period 96 hours after emergence of adult life. The results of this study has clearly shown that the concentration $0.1 \%$ of Piper nigrum aqueous extract gave a highly significant inhibitory effect on the growth development of the ovaries and their follicles.
\end{abstract}

Key words: Aqueous extract, Culex pipiens, Ethanolic extracts, Larvae, Piper nigrum, The ovary.

\section{Introduction:}

The mosquito $C$. pipiens molestus $\mathrm{F}$. belongs to the family Culicidae of the order Diptera which constitute a major public health menace as vectors of serious human diseases (1). C. pipiens is the vector of the West Nile Virus (WNV) that causes encephalitis or meningitis. (WNV) distributed throughout Africa, the Middle East and Southern temperate Eurasia and was recently introduced into North America as well (2). Mosquito as vectors for transmission of serious diseases that cause morbidity, mortality, economic loss and social disruption such as malaria, lymphatic filariasis and viral diseases is welldocumented (3).

The only way of reducing the incidence of these diseases is by mosquito control, which is frequently dependent on applications of conventional synthetic insecticides (4). Control of insects generally requires the use of chemical insecticides that are toxic to humans and domestic animals and also harmful to the environment (5) . More than 189 plant families have been known to produce chemical factors and metabolites of value in biological control programs (6).

Department of Biology, College of science, University of Mosul, Mosul, Iraq.

E-mail: alfsbio76@uomosul.edu.iq

*ORCID ID: 0000-0002-9805-3236
A number of such plant products have been used for insects control such as oils as efficient mosquito larvicides and repellents without posing hazards of toxicity to humans (7). The plant has been credited with interesting pesticidal properties against insects and fungi of agricultural significance, including repellent properties against mosquito species (8) (9).

Piper nigrum known as king of spices is one of the oldest spice crops that originated from India and distributed to other countries (10). This plant has a number of active chemical compounds such as piperyline, piperettine, volatile oils, phenolic compounds, b-carotene, lauric acid, myristic acid and piperine which have several biological activities that effect insects, Black pepper have high repellency against malaria vector (11) (12).

The aim of this study was to investigate the toxicity of the aqueous and alcoholic extracts of Piper nigrum and its effect on mosquito larvae Culex pipiens (Culicidae) .

\footnotetext{
Material and Methods:

Preparation of ethanolic extract from $P$. nigrum seeds

The seeds of $P$. nigrum obtained from local market and grounded by electric miller to obtain a fine powder that was preserved in dark flask at $0 \mathrm{C}^{\circ}$
} 
temperature up to the preparation of the extract. About $20 \mathrm{~g}$ of the powder was soaked separately in a flask containing $400 \mathrm{ml}$ of $97 \%$ ethanol. The mixture was stirred for 30 minutes, then the extract left at laboratory temperature for 24 hours The resulting mixture was filtered using many layers of gauze then filtered again through Whatmam No.1 filter paper and the solvent was evaporated by heating in oven at $45 \mathrm{C}^{\circ}$ (13). The dry powder was stored in clean and dry container in the refrigerator. $1 \mathrm{gm}$ of this powder was dissolved in $5 \mathrm{ml}$ of $97 \%$ ethanol and the volume completed to $10 \% \mathrm{ml}$ by the same solvent to obtain a stock solution with a concentration of $10 \%$ from this stock solution different concentrations of $0.5,1,1.5 \mathrm{ppm}$ were prepared.

\section{Preparation of aqueous extract from $P$. nigrum seeds}

About $50 \mathrm{gm}$ of the powder was soaked in flask containing $300 \mathrm{ml}$ of distilled water. The mixture was stirred for 1 hours then the extract was kept in the refrigerator for 24 hour, then the extract was filtered by many layers of gauze and the filtrate filtered again through Whatmam No.1 filter paper and dried by the lyophilizer. The dry powder stored in clean and dry container in the refrigerator (14). 1 $\mathrm{g}$ of this powder was dissolved in $5 \mathrm{ml}$ of distilled water and volume completed to $10 \mathrm{ml}$ by distilled water to obtain a stock solution with concentration of $10 \%$ from this stock solution different concentrations of $0.1,0.2,0.5,1,2.5,5 \%$ were prepared.

\section{Mosquito culture}

The egg rafts were collected from the culture $C$. pipiens mosquito from laboratory of entomology in university of Mosul college of Education in September of 2013. The egg rafts transferred into enamel trays containing $(2 \mathrm{~L})$ dechlorinated tap water with two egg rafts per tray. The larvae were fed with $2.3 \mathrm{gm}$ per tray of feed rabbits(yellow corn, wheat, protein, dry milk) which was brought from College of Vertenary Medicine. Adult mosquitoes were fed on $10 \%$ sugared solution and after 3-4 days periodically blood-feeding within night on naked chest pigeon. Laboratory condition modulated at 12-12 light/dark interval periods, $28 \pm$ $2 \mathrm{C}^{\mathrm{o}}$ and $70 \pm 10 \%$ relative humidity larvicidal bioassay (15).

All the experiments were triplicated for each concentration, and control used parallel to each experimental series with adding ethanol solvent equal to that of ethanolic extract in the applied solution but in aqueous extract only water was added in control breeding.
A healthy $3^{\text {rd }}$ instar larvae of culex pipiens molestus were exposed in a disposable plastic cup containing $50 \mathrm{ml}$ of treatment solution of three concentrations of ethanolic extract $0.5,1,1.5 \mathrm{ppm}$ and five concentrations of aqueous extract $0.1,0.2$, $0.5,1,2.5,5 \%$. Twenty healthy larvae were collected and placed into plastic cup with 0.3 grams amount of food. The effect of the extracts were monitored by counting the dead larvae at the end of 24, 48 hours and continuing for 7 days, and the mortality values were calculated:

Percentage mortality $=$ number of dead larvae $/$ number of larvae introduced $\times 100$

The remaining larvae of $0.1 \%$ concentration were bred until they turned into adults, the males were killed, the females were raised in vial containing a small piece of cotton saturated with sugared solution $10 \%$. The nozzle of vial was covered with a thin layer of gauze to allow the air to enter the vial until they reached the age of 96 hours after their emergence. The females were fixed with Bowen's solution (16). and annotated under a dissecting microscope to obtain the ovaries which were stained with pigments Light green and Orange G.(17). The results were modified according to equation Abbott (1925).

Correct percent of mortality $=\frac{T-C}{100-C} \times 100$

Where, $\mathrm{T}=$ The percentage of mortality in the treatment

$\mathrm{C}=$ The percentage of mortality in the control

Percentage mortality $=\frac{\text { Number of dead larvae }}{\text { Number of larvae introduced }} \times 100$

\section{Results and Discussion:}

Table (1) is showing the larval activity of ethanolic extract from seeds of Piper nigrum against $3^{\text {rd }}$ instar larvae of Culex pipiens molestus $\mathrm{F}$. The concentrations $1.5,1 \mathrm{ppm}$ respectively may be the cause of a higher percentage of killed larvae in the first day of experiment, which was $75,70 \%$ respectively. As for the concentration $0.5 \mathrm{ppm}$ gave mortality percent of $60 \%$. In the second day of the experiment outweigh the concentration $1 \mathrm{ppm}$ is killing all the larvae, where the percentage of killing was $100 \%$. The 0.5 ppm concentration killed $100 \%$ of the larvae in the fifth day of the experiment. Note that there was no mortality in the control treatment during the experiment for all concentrations. 
Table 1. The effect of ethanolic extract of Piper nigrum on $3^{\text {rd }}$ instar larvae of Culex pipiens .

\begin{tabular}{ccccc}
\hline & \multicolumn{4}{c}{ Concentrations ppm } \\
\cline { 2 - 5 } days & $\mathbf{0 . 5}$ & $\mathbf{1}$ & $\mathbf{1 . 5}$ & Control \\
& \multicolumn{4}{c}{ Mortality percentage $\%$} \\
$\mathbf{1}$ & 60 & 70 & 75 & 0 \\
$\mathbf{2}$ & 65 & 100 & 100 & 0 \\
$\mathbf{3}$ & 70 & 100 & 100 & 0 \\
$\mathbf{4}$ & 85 & 100 & 100 & 0 \\
$\mathbf{5}$ & 100 & 100 & 100 & 0 \\
\hline
\end{tabular}

Table (2) shows the larval activity of aqueous extract of Piper nigrum against $3^{\text {rd }}$ instar larvae of Culex pipiens molestus $\mathrm{F}$., data given in the above table indicates on day one of experiment that the $5 \%$ concentration was the most affective on larval mortality which was $90 \%$. As for the concentration $2.5 \%$ the percentage of death $80 \%$, while the concentration $0.1 \%$ caused a lower percentage of mortality $10 \%$. In the second day of experiment the concentration $5 \%$ gave mortality percent $100 \%$, while the concentration $2.5 \%$ gave mortality of a $100 \%$ in the fourth day of the experiment . But the concentration $0.1 \%$ caused a lower percentage of mortality $25 \%$ in the fifth day of the experiment which remained constant until the seventh day. Note that there was no mortality in the control treatment during the experiment for all concentrations.

Table 2. The effect of aqueous extract of Piper nigrum on $3^{\text {rd }}$ instar larvae of Culex pipiens .

\begin{tabular}{lccccccc} 
Days & \multicolumn{7}{c}{ Concentrations \% } \\
\cline { 2 - 8 } & $\mathbf{0 . 1}$ & $\mathbf{0 . 2}$ & $\mathbf{0 . 5}$ & $\mathbf{1}$ & $\mathbf{2 . 5}$ & $\mathbf{5}$ & Control \\
& & & \multicolumn{7}{c}{ Mortality percentage \% } & & \\
$\mathbf{1}$ & 10 & 20 & 40 & 60 & 80 & 90 & 0 \\
$\mathbf{2}$ & 12 & 25 & 60 & 60 & 80 & 100 & 0 \\
$\mathbf{3}$ & 15 & 30 & 65 & 72 & 95 & 100 & 0 \\
$\mathbf{4}$ & 15 & 40 & 70 & 85 & 100 & 100 & 0 \\
$\mathbf{5}$ & 25 & 40 & 70 & 85 & 100 & 100 & 0 \\
$\mathbf{6}$ & 25 & 40 & 70 & 95 & 100 & 100 & 0 \\
$\mathbf{7}$ & 25 & 40 & 70 & 95 & 100 & 100 & 0 \\
\hline
\end{tabular}

The results of the current study showed that the ethanolic extract and aqueous extract of black pepper used against $3^{\text {rd }}$ instar larvae of Culex pipiens molestus had a great effect on mortality rate after 24 hours up to 7 days of treatment, and this effect is increased by increasing concentration, and this may be due to disorders in the nervous system of the insect, causing poisoning and death (18). The effect of black pepper extract on the nervous system is due to the presence of amides (pyrolidin amide) and piperine in large quantities in the extract of black pepper (19). The results of the current study are similar to those found by (20) who proved that the effect of aqueous, methanolic extracts and essential oil on Anopheles gambiae larvae, maximum $100 \%$ concentration of the essential oils Curcuma longa and P. nigrum oils gave $95.7 \%$ and $95.3 \%$ protection respectively therefore $P$. nigrum and Curcuma longa can serve as repellents against Anopheles gambiae, and can be used in integrated vector management control programs. The correlation was $0.84,0.94$, and 0.96 for essential oils, aqueous and methanolic extracts of Piper nigrum, respectively.The results of this study are consistent with the findings of (6) that the water extract of Piper nigrum showed a high level of biological activity against the second larval instar of Sarcophaga haemorrhoidalis which fed on treated diet ,it induced prolongation in the larval duration, great reduction in larval weight and the larval mortality increased. The current study are similar to those found by (21) that the powder of black pepper and piperine mixtures caused high mortality in the Anopheles gambiae strains, with black pepper proving significantly more toxic than piperine. The results of the current study are similar to those of (11), which proved that the different concentrations of alcoholic extract and crude powder of black pepper seeds caused a significant decrease in all aspects of life for the first and second generation of Callosobruchus maculatus. This study is consistent with the findings of (7), that the etheric extract of Piper nigrum caused higher mortality towards all target pests, the mortality percentage reached $100 \%$ at a concentration of $2.5 \%(\mathrm{w} / \mathrm{w})$ after 21 day of treatment of adult rice weevil. The obtained results from this research nearly agreed with those for using the ethanol extract for some plants, including black pepper against Tribolium castanium which had a significant effect on the mortality rates of the adult of Tribolium castanium after 24 hours of treatment. This effect increased with increasing concentration and the mortality percentage reached to $100 \%$ after 7 days of treatment at the concentration of $2 \%(22)$. 


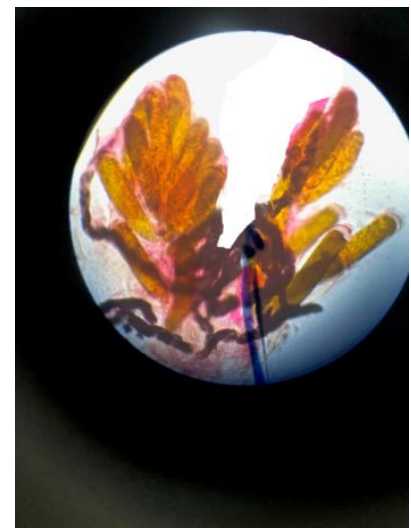

Figure 1. A) The ovaries for adult control models of mosquito $C$. pipiens 96 hours after the adult emergence power zoom (10x).
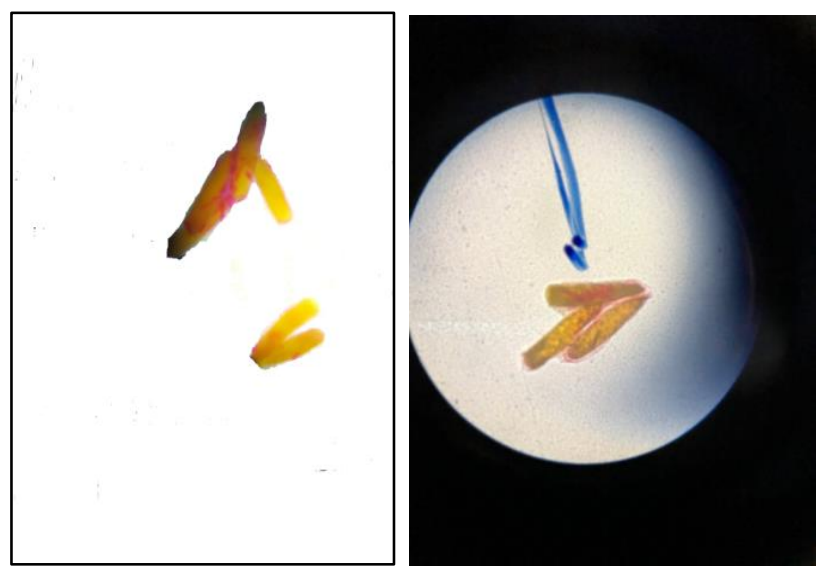

Figure 2. A) A number of ovarian follicles taken from the ovaries of control models of mosquito C. pipiens 96 hours after the adult emergence . power zoom (10x).

Explain the results of Anatomy and the application of $0.1 \%$ concentration of aqueous extracts of the seeds of Piper nigrum has led to the appearance of a variety of abnormalities in the ovaries of females obtained from the treatment of the third larval instars of the mosquito, Culex pipiens molestus $\mathrm{F}$., with this concentration. Where the inhibitory effect of growth of the ovaries Fig. (1 B) and kept their small follicles in the spherical form Fig (2 B) compared to the control models in which the ovary is large in size Fig. (1 A) and completed growth of ovarian cells and the females are ready and the shape of eggs is a long-like banana and filled with yolk. Fig. (2 A).

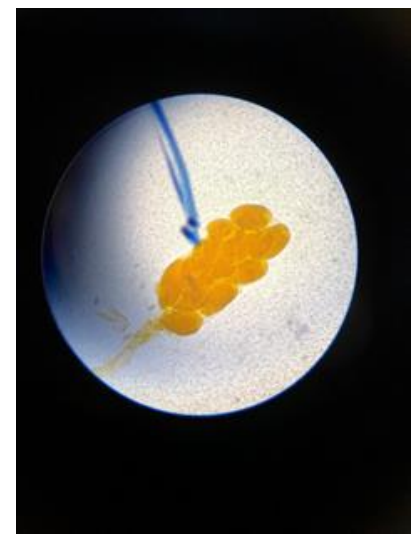

Figure 1. B) The ovary of adult mosquito obtained from the treatment of 3rd instar larvae of $C$. pipiens with concentration $0.1 \%$ of aqueous extract of $P$. nigrum 96 hours after the adult emergence .power zoom (10x).

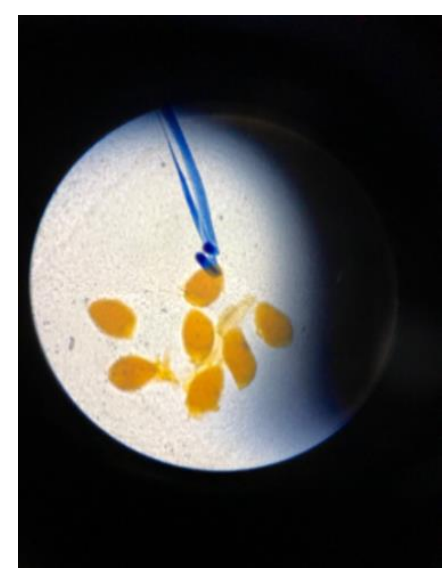

Figure 2. B) A number of ovarian follicles taken from the ovaries of adult mosquito obtained from the treatment of 3 rd instar larvae of $C$. pipiens with concentration $0.1 \%$ of aqueous extract of $P$. nigrum 96 hours after the adult emergence power zoom (10x).

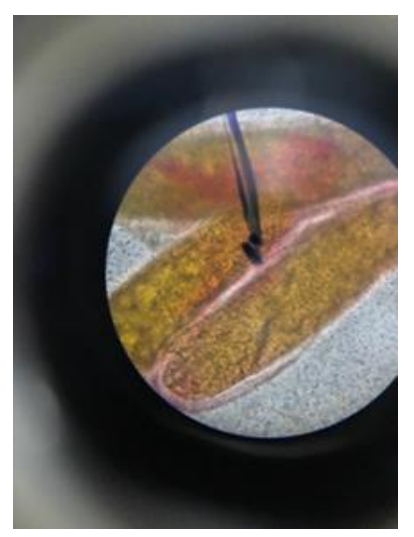

Figure 2. A) power zoom (40x).

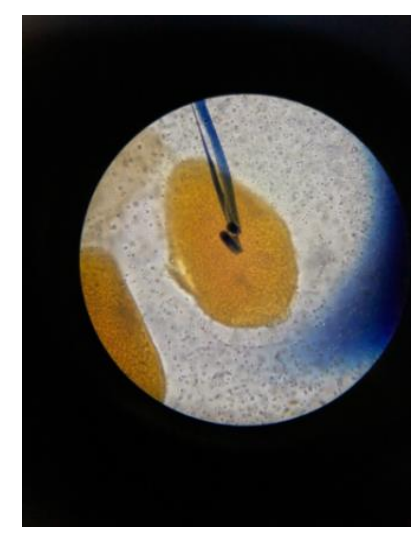

Figure 2. B) power zoom (40x). 
The treatment of the third larval instars of the mosquito $C$. pipiens showed $0.1 \%$ concentration of the aqueous extract of black pepper had inhibitory growth effect on the female ovaries from these treated larvae after 96 hours of emergence and the case of inhibition of growth of the ovaries and ovarian follicles caused by the use of this concentration and preventing them from reaching maturity and the main reason is the lack of certain hormones responsible for the growth of the ovaries and their natural development or low concentrations of natural causes therefore the different nerve and non-nerve endocrine may play a role (17). The current study is similar to those observed by (23) of the use of $1 \mathrm{ppm}$ of azadirachtin solution against mosquito with a light sweep before being transferred to hatching water led to inhibition of hatching and larval formation. This study is consistent with (24) findings that the inhibitory effect of the $25 \mathrm{ppm}$ concentration of plant Callisteman lanceolatus extract which caused a clear decrease in the size of the ovaries and their weight growth and development. (25) noted the inhibitory effect of plant extracts, which caused a significant decrease in juvenile hormone $(\mathrm{JH})$, ovarian growth and development in mosquito Culex pipiens and A aegypti. (26) finding the effect of different concentrations $(2,4,6,8$ and $10 \mu \mathrm{g} / \mu$ doses $)$ of Andrographolide extract on the reproductive system of the Papilio demoleus, in their observations various morphological abnormalities like deformation and degeneration were observed in the ovaries and accessory glands of sterile insects.

\section{Conclusion:}

According to obtained results, high toxicity of Piper nigrum to mosquito larvae may be synthetic insecticide but are ecofriendly alternatives. Also, relatively short residual persistence can allow the use of potential plant extracts with high sensitivity and biodegrade easily within 9-15 days. Further work on other Culex pipiens stages and the effect of the sub lethal concentration on the ovary of adult are needed.

\section{Acknowledgment}

The author are very grateful to the University of Mosul/College of Science/department of Biology for their provided facilities, which helped to improve the quality of this work .

\section{Conflicts of Interest: None.}

\section{The author has signed on animal welfare statement: None}

\section{References:}

1. Mekhlif AF. Larvicidal efficacy and residual toxicity of selected xerophyte plants against Culex pipiens molestus mosquito. Int J Mosq Res. 2017; 4(3): 117-22.

2. Brugman VA, Hernandez-Triana LM, Medlock JM, Fooks AR, Carpenter S, Johnsonn N. The role of Culex pipiens L. (Diptera:Culicidae) in virus transmission in Europe. Int $\mathbf{J}$ Environ Res Public Health. 2018;15:389.

3. Okbatinsae G, Haile A. In vitro studies of larvicidal effects of some plant extracts against Anopheles gambiae larvae larvae (Diptera:Culicidae) J Medic Plan Res. 2017; 11(4):66-72 .

4. Rathy MC, Sajith U, Harilal C. Larvicidal efficacy of medicinal plant extracts against the vector mosquito Aedes albopictus . Int J Mosq Res. 2015; 2(2):80-82 .

5. Al-Qazwini Y.M. and EL-Essa R.A. Effect of use aggregation pheromone to reducing the amount of pesticides that needed to control American cockroaches Periplaneta Americana (L). ( Blattodea : Blattidae) IOP Conf. Series: Materials Science and Engineering 2019; $571: 1-15$

6. Asiri BM . The biological effects of the water extract of Piper nigrum (Fam:Piperaceae) seeds on the larvae of Sarcophaga haemorrhoidalis (Fallen) (Diptera: Sarcophagidae). Life Sci J. 2014; 11(7):444-54.

7. Hussein AE, Abd Elhaseeb H, Mohamed RA, AbdelMogib M, Abou Elnaga Z. Toxicity of three chemical extracts of black pepper fruits against two stored grain insect pests. Int J Pharm Sci Inven. 2017; 6(10):20-29.

8. Ali A, Wang YH, Khan IA. Larvicidal and biting deterrent activity of essential oils of Curcuma longa Arturmerone and Curcuminoids against Aedes aegypti and Anopheles quadrimaculatus (Culicidae: Diptera) J Med Ent. 2015; 52(5):979-986.

9. Tisgratog R, Sanguanpong U, Grieco JP, NgoenKluan $R$, and Chareonvirivanhan T. Plants traditionally used as mosquito repellent and the implication for their use in vector control . Acta Tropica. 2016; 157:136-44.

10. Daba T, Kifelew H, Hailemichael G, Getachew W. Insect pests infesting black pepper (Piper nigrum L.) in southwestern part of Ethiopia. Afr J Agr Res 2017; 12(21):1817-23.

11. Aljoboory RK. Evaluating the efficiency of the fruits of black pepper on some aspects of the life of the insect beetle south cowpea Callosobruchus maculatus (F.) (Coleoptera:Bruchidae). Call Bas Edu Res j. 2017; 23(97):165-75.

12. Ahmed N, Fazal H, Abbasi BH, Farooq S, Ali M, Khan MA . Biological role of Piper nigrum L. (black pepper):Areview. Asi Paci J Trop Biomed. 2012; S1945-S1953.

13. Harborne JB. Phytochemical methods. $2^{\text {nd }}$ ed.Chapman \& Hall. London. NewYork. 1984. 288 pp.

14. Riose JI, Recio MC, Villar A. Antimicrobial activity of selected plant employed in the Spanish Mediterranean area $\mathrm{J}$ Ethm Pharm. 1987 ; 21 : 143-152. 
15. Al-Sharook ZM, Balan K, Jiang Y, Rembold H. Stem bark extract of the pine tree Pinus halepensis as mosquito larvicide. J Appl Ent. 1991; 111:425-30.

16. Luna LG. Manual of histological staining methods. $1^{\text {st }}$ Ed. New York:McGraw Hill Book Company, 1968 ; 37-40 pp.

17. Gorgees NS. Study of the ovarian histology and vitellogenesis in the autogenous mosquito Culex pipiens molestus Forskal (Diptera,Culicidae). PhD. Thesis, Mosul University .1996.

18. Muthr-Krishnan J, Pushpalatha E. Effects of plant extraction fecundity and fertility of Mosquitoes J. Appl. Entomol. 2001; 125:31-35

19. Elliott M, Farnham AW, Sewicki RM. Insecticidal amides with selective potency against a resistant strain of house flies -Agric. Biol. Chem . 1986; 50:1347-1349.

20. Kemabonta KA, Adediran OI, Ajelara KO. The insecticida efficacy of the extracts of Piper nigrum (black pepper) and Curcumna longa (Turmeric) in the control of Anopheles gambiae Giles (Dip., Culicidae). Jor J Biolo sci.2018; 11(2):195-200.

21. Samuel M, Oliver SV, Coetzee M, Brooke BD. The larvicidal effects of black pepper (Piper nigrum L.) and piperine against insecticide resistant and susceptible strains of Anopheles malaria vector mosquitoes. Para Vec. 2016; 9:238-47.

22. Ismail HM, El-Delimy RH. The toxic effect of some plant extracts on adults red flour beetle, Tribolium castaneum (Herbst) (Coleoptera:Tenebrionidae) . J Pur Appl Sci. 2017; 16(1):98-106.

23. Su T, Mulla MS. Ovicidal activity of neem products (azadirachtin) against Culex tarsalis and Culex quinquefasciatus . (Diptera:Culicidae) . J Am Mosq Con Asso. 1998; 14:204-209.

24. Neraliya S, Srivastava U. Effect of crude extract of Australian bottlebrush Callistemon lanceolatus (Myrtaceae) on fecundity and reproductive organ of mosquito Culex quinquefasciatus. J Adv Zool. 2000; 21:88-91.

25. Lee S, Oh H, Fang Y, An S, Park D, Song H, et al. Identification of plant compounds that disrupt the insect juvenile hormone receptor complex . App Bio Sic. $2015 ; 112(6): 1733-38$.

26. Vattikonda SR, Madhavi M, Raja S. Effect of Andrographolide on ovarian development of Papilio demoleus L. (Lepidoptera:Papilionidae) larvae. Int $\mathbf{J}$ Ent Res; (2018; 3(2):23-27.

\title{
Culex عiper nigrum L. تلثى يرقات البعوض المستخلص المائي والكحولي للفلقل الاسود pipiens molestus Forskal
}

\author{
الفت تحسين ياسين \\ قسم علوم الحباة، كلية العلوم، جامعة الموصل، الموصل، العراق .

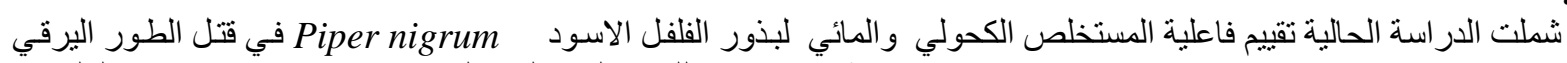

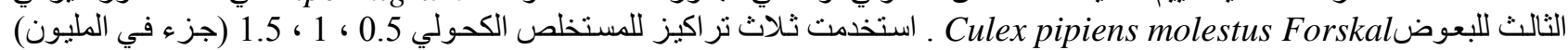

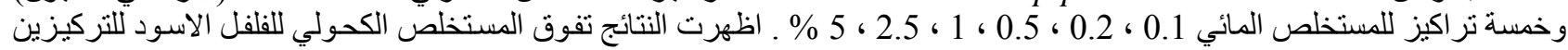

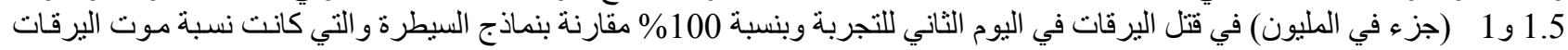

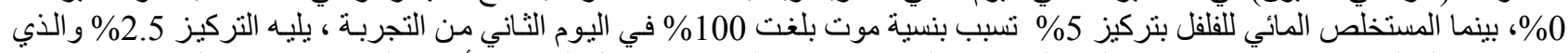

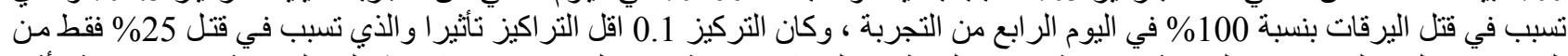

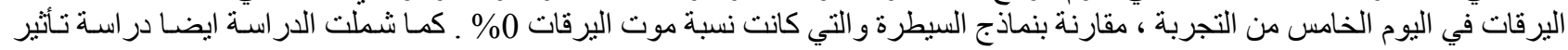

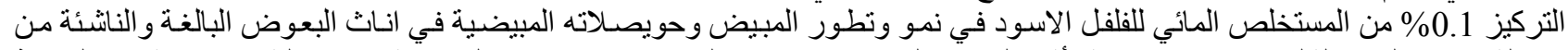

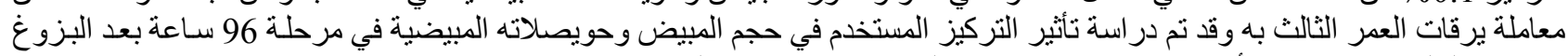

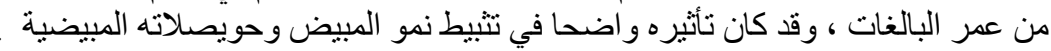 \\ الكلمات المفتاحية: البعوض C. Pipiens ، الفلفل الاسود، المستخلصات، تأثير، اليرقة، المبيض.
}

